\title{
Incidence of gonorrhoea in Denmark, 1957-1971*
}

\author{
INGA LIND \\ Neisseria Department, WHO International Reference Centre for Gonococci, Statens Seruminstitut, DK-2300 \\ Copenhagen S., Denmark
}

\begin{abstract}
All cases of gonorrhoea in Denmark in which the diagnosis is based on the culture of gonococci are registered at the Neisseria Department, Statens Seruminstitut, Copenhagen, the only exceptions being cases found in Greenland. The data registered have been compared with those reported to the National Health Service, and a breakdown of age and sex distribution has been made. The register cannot form the basis of a sociological study, since no information of a personal nature is included.
\end{abstract}

\section{Material}

Each case of gonorrhoea in which more than 3 weeks have elapsed since the last positive culture is registered as a new case, and the following data are recorded: age and sex of patient, place of treatment, number and origin of specimens positive by culture. Specimens originating from the urethra, cervix, and rectum are designated $U, C$, and $R$ respectively.

During the 15-year period investigated, the procedure used for isolation and identification of Neisseria gonorrhoeae at the Statens Seruminstitut has undergone radical changes. A selective medium of the Thayer-Martin type was introduced gradually (Reyn, 1969; Reyn and Bentzon, 1972), and since 1970 the identification of gonococcal colonies has been made by means of an immunofluorescent technique (Lind, 1967; Lind, 1969). Specimens from more unusual sites, (e.g. the pharynx) are still subjected to further bacteriological examination.

The annual number of specimens examined for gonococci by culture rose from 76,000 in 1957 to 285,000 in 1971 (the latter figure includes 18,000 specimens examined at the newly established regional laboratories). The ratio between specimens received from female and male patients changed from 4:1 in 1957 to $3: 1$ in 1971 .

The census of cases was made mainly for 5-year age groups. In 1963 the form of notification to the National Health Service was changed, and an additional analysis by age groups has since been made (Table II). The statistical analysis was performed by $\mathrm{S}$. Olesen Larsen,

Received for publication December 8, 1972

*This study was supported by grants from the World Health Organization

Address for reprints: Dr. Inga Lind, Neisseria Department, Statens Seruminstitut, Amager Boulevard 80, 2300 Copenhagen S., Denmark actuary at the Department of Biostatistics, Statens Seruminstitut.

\section{Results}

Fig. 1 shows the annual number of cases of gonorrhoea reported to the National Health Service from 1928 to 1971 , and also the annual number of cases per 100,000 inhabitants. Since 1966 the incidence of gonorrhoea has risen considerably, and it is now at the highest level demonstrated since the second world war (1971 : 316 per 100,000).

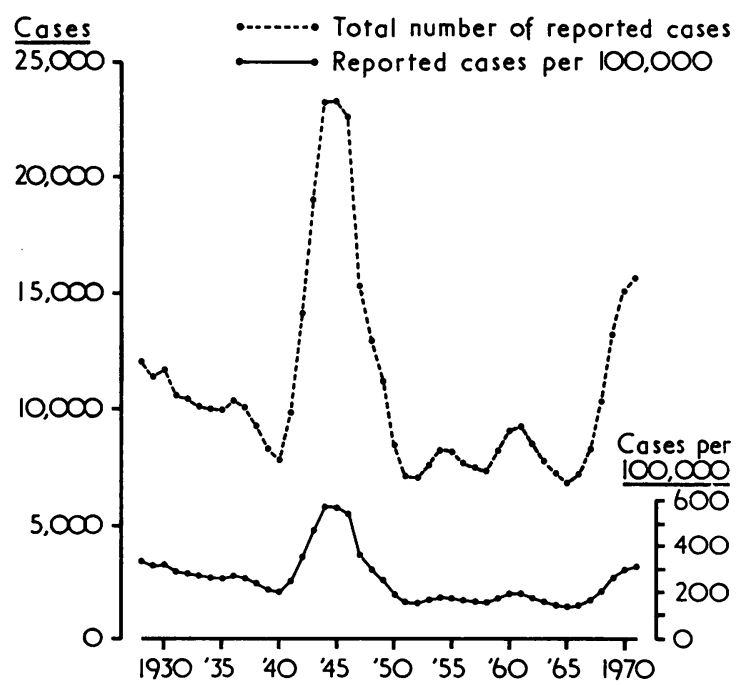

FIG. 1 Gonorrhoea in Denmark. Annual number of cases reported to the National Health Service 1928-1971 and annual morbidity rate expressed as the number of cases per 100,000 inhabitants

Comparison of cases registered at the Neisseria Department with those reported to the National Health Service

The annual number of cases registered at the Neisseria Department has increased steadily since 1957 
(Table I). In 1970 and 1971 the numbers of registered cases and reported cases were approximately the same.

TABLE I Gonorrhoea in Denmark. Number of cases reported to the National Health Service and registered at the Neisseria Department, Statens Seruminstitut, Copenhagen

\begin{tabular}{|c|c|c|}
\hline \multirow[b]{2}{*}{ Year } & \multicolumn{2}{|c|}{ No. of cases } \\
\hline & Reported & Registered \\
\hline $\begin{array}{l}1957 \\
1958 \\
1959 \\
1960 \\
1961 \\
1962 \\
1963 \\
1964 \\
1965 \\
1966 \\
1967 \\
1968 \\
1969 \\
1970 \\
1971\end{array}$ & $\begin{array}{r}\mathbf{7 , 4 4 7} \\
\mathbf{7 , 3 1 4} \\
\mathbf{8 , 1 9 4} \\
\mathbf{9 , 0 5 5} \\
\mathbf{9 , 2 4 4} \\
\mathbf{8 , 5 0 2} \\
\mathbf{7 , 7 5 2} \\
\mathbf{7 , 2 1 9} \\
\mathbf{6 , 8 3 9} \\
\mathbf{7 , 1 6 2} \\
\mathbf{8 , 2 4 0} \\
10,295 \\
13,172 \\
15,044 \\
15,646\end{array}$ & $\begin{array}{r}3,983 \\
4,459 \\
5,127 \\
6,416 \\
7,044 \\
6,515 \\
5,927 \\
5,870 \\
6,139 \\
5,966 \\
7,599 \\
9,775 \\
12,800 \\
15,067 \\
15,585\end{array}$ \\
\hline
\end{tabular}

Fig. 2 illustrates the relationship between the annual number of reported and registered cases for male and female patients respectively. The number of reported cases of male gonorrhoea has constantly exceeded those in which diagnosis was confirmed by culture of gonococci (1971: +13 per cent.). Since 1960 the number of registered cases of female gonorrhoea has exceeded those reported to the National Health Service (1971: +15 per cent.). In 1971 the male: female ratio for reported cases was $1 \cdot 4: 1$ and for registered cases $1 \cdot 1: 1$.
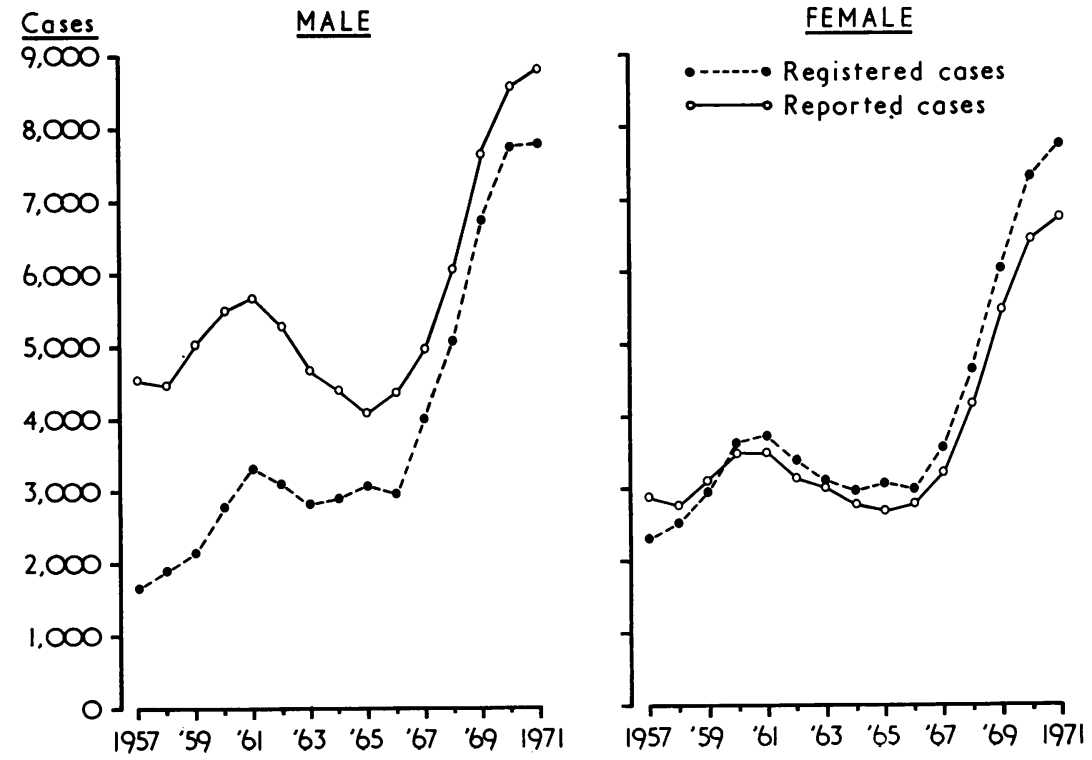

The number of registered cases in the different age groups has been compared for each year with the number of reported cases in the same groups. Table II shows the figures for 1971. The majority of the non-reported cases are females aged 13 to 19 years and the majority of non-registered cases are males in the large 20 to 44-year age group.

TABLE II Gonorrhoea in Denmark 1971. Comparison of cases reported to the National Health Service with those registered at the Neisseria Department, Statens Seruminstitut

\begin{tabular}{|c|c|c|c|c|}
\hline \multirow{3}{*}{$\begin{array}{l}\text { Age group } \\
\text { (years) }\end{array}$} & \multicolumn{4}{|l|}{$\operatorname{Sex}$} \\
\hline & \multicolumn{2}{|l|}{ Male } & \multicolumn{2}{|l|}{ Female } \\
\hline & Registered & Reported & Registered & Reported \\
\hline $\begin{array}{c}\leqq 1 \\
1-12 \\
13-15 \\
16-19 \\
20-44 \\
\geqq 45\end{array}$ & $\begin{array}{r}- \\
2 \\
23 \\
1,037 \\
6,708 \\
167\end{array}$ & $\begin{array}{l}- \\
- \\
24 \\
1,278 \\
7,546 \\
143\end{array}$ & $\begin{array}{r}-\quad 7 \\
291 \\
2,807 \\
4,466 \\
77\end{array}$ & $\begin{array}{r}- \\
3 \\
154 \\
2,268 \\
4,161 \\
69\end{array}$ \\
\hline Total & 7,937 & 8,991 & 7,648 & 6,655 \\
\hline
\end{tabular}

Age distribution

An example (1969) of the age distribution of female and male patients with gonorrhoea is given in Fig. 3 (overleaf).

For females, the highest morbidity is found at 19 to 20 years of age and for males at 23 to 24 years of age. During the period investigated, no appreciable change took place in the position of the peak. For example, Fig. 4 (overleaf) shows the age distribution curves for female patients in 1966 and 1970.

\section{FEMALE}

F I G.2 Annual number of cases reported to the National Health Service compared with those registered at the Neisseria Department, Statens Seruminstitut, by sex. 




FIG. 3 Age distribution of registered cases of gonorrhoea in women (5,960 cases) and in men (6,840 cases) in 1969

Tables III and IV show the distribution into 5 -year age groups in 1971 . About 80 per cent. of all women with gonorrhoea were below 25 years of age and only 2 per cent. were more than 40 years old.

TABLE III Gonorrhoea in men, 1971. Cases registered at Statens Seruminstitut

\begin{tabular}{|c|c|c|c|}
\hline $\begin{array}{l}\text { Age group } \\
\text { (yrs) }\end{array}$ & Number & Per cent. & Per 100,000 \\
\hline $\begin{array}{c}\leqq 14 \\
15-19 \\
20-24 \\
25-29 \\
30-34 \\
35-39 \\
\geqq 40\end{array}$ & $\begin{array}{r}12 \\
1,050 \\
3,440 \\
2,077 \\
724 \\
318 \\
316\end{array}$ & $\begin{array}{r}0 \cdot 2 \\
13 \cdot 2 \\
43 \cdot 3 \\
26 \cdot 2 \\
9 \cdot 1 \\
4 \cdot 0 \\
4 \cdot 0\end{array}$ & $\begin{array}{r}- \\
548 \\
1,619 \\
1,034 \\
464 \\
226 \\
-\end{array}$ \\
\hline Total & 7,937 & $100 \cdot 0$ & - \\
\hline
\end{tabular}

TABLE IV Gonorrhoea in women, 1971. Cases registered at Statens Seruminstitut

\begin{tabular}{|c|c|c|c|}
\hline $\begin{array}{l}\text { Age group } \\
\text { (yrs) }\end{array}$ & Number & Per cent. & Per 100,000 \\
\hline $\begin{array}{c}\leqq 14 \\
15-19 \\
20-24 \\
25-29 \\
30-34 \\
35-39 \\
\geqq 40\end{array}$ & $\begin{array}{r}79 \\
3,026 \\
2,771 \\
1,105 \\
387 \\
135 \\
145\end{array}$ & $\begin{array}{r}1 \cdot 0 \\
39 \cdot 6 \\
36 \cdot 2 \\
14.5 \\
5 \cdot 1 \\
1 \cdot 8 \\
1.9\end{array}$ & $\begin{array}{r}- \\
1,672 \\
1,386 \\
587 \\
257 \\
-97\end{array}$ \\
\hline Total & 7,648 & $100 \cdot 1$ & - \\
\hline
\end{tabular}

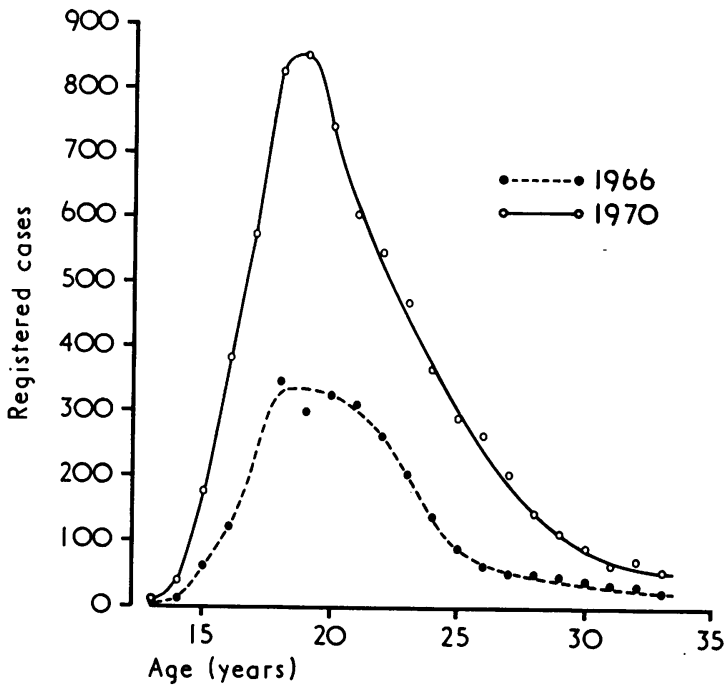

FIG. 4 Age distribution of registered cases of gonorrhoea in women in 1966 (2,959 cases) and in $1970(7,213$ cases $)$

Among male patients with gonorrhoea, 43 per cent. were 20 to 24 years old. No essential displacement in the percentage distribution into age groups occurred during the years 1966 to 1971 when the morbidity increased drastically.

In order to evaluate the changes in the age distribution of patients with gonorrhoea in relation to such changes in the whole population, the number of cases per 100,000 inhabitants was calculated for each 5 -year age group. Fig. 5 shows the changing morbidity in the 15 to 30 -year age groups. For male patients, the increasing morbidity showed an even distribution in the various groups, thus resulting in parallel curves. The same was essentially true for female patients aged 20 to 24 and 25 to 29 years, whereas there were significant changes in the morbidity in the 15 to 19-year old females. There was a small peak around 1960-61 and a steep increase after 1968. In 1971 the morbidity for that group was 1,672 per 100,000 , i.e. the highest morbidity in any 5 -year age group in that year.

Table V shows further details of the 15 to 19-year old female patients. The proportion of all the female cases of gonorrhoea comprised in that group was greatest in 1961 (43 per cent.). When expressed as the number of cases per 100,000 inhabitants, the morbidity for $1971(1,672)$ was the highest up to now. 


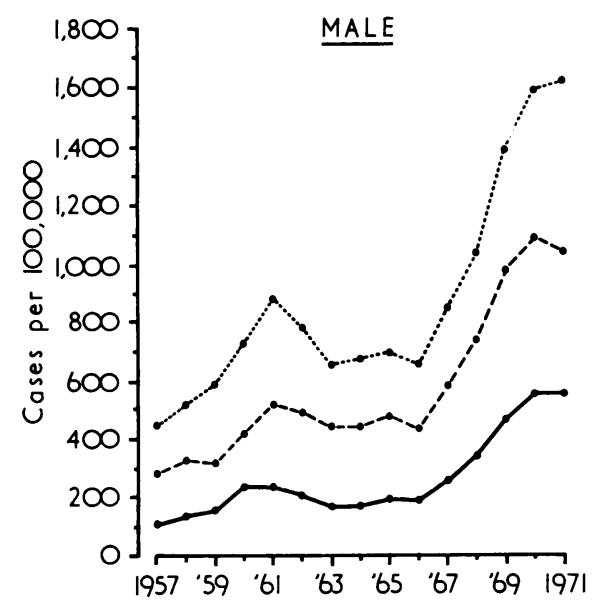

TABLE V Gonorrhoea in women in Denmark. Cases registered at Statens Seruminstitut

\begin{tabular}{|c|c|c|c|c|}
\hline \multirow{2}{*}{ Year } & \multirow{2}{*}{ All ages } & \multirow{2}{*}{15 to 19 yrs } & \multicolumn{2}{|c|}{15 to 19-year age group } \\
\hline & & & Per cent. & Per 100,000 \\
\hline $\begin{array}{l}1957 \\
1958 \\
1959 \\
1960 \\
1961 \\
1962 \\
1963 \\
1964 \\
1965 \\
1966 \\
1967 \\
1968 \\
1969 \\
1970 \\
1971\end{array}$ & $\begin{array}{l}2,299 \\
2,525 \\
2,934 \\
3,581 \\
3,681 \\
3,357 \\
3,075 \\
2,934 \\
3,027 \\
2,959 \\
3,530 \\
4,609 \\
5,960 \\
7,213 \\
7,648\end{array}$ & $\begin{array}{r}748 \\
791 \\
1,002 \\
1,485 \\
1,583 \\
1,382 \\
1,268 \\
1,114 \\
1,161 \\
1,039 \\
1,281 \\
1,614 \\
2,246 \\
2,809 \\
3,026\end{array}$ & $\begin{array}{l}32 \cdot 5 \\
31 \cdot 3 \\
34 \cdot 2 \\
41 \cdot 5 \\
43 \cdot 0 \\
41 \cdot 2 \\
41 \cdot 2 \\
38 \cdot 0 \\
38 \cdot 3 \\
35 \cdot 1 \\
36 \cdot 3 \\
36 \cdot 3 \\
37 \cdot 7 \\
38 \cdot 9 \\
39 \cdot 6\end{array}$ & $\begin{array}{r}461 \\
466 \\
555 \\
775 \\
826 \\
680 \\
610 \\
532 \\
565 \\
520 \\
641 \\
868 \\
1,228 \\
1,545 \\
1,672\end{array}$ \\
\hline
\end{tabular}

Supplementary count for 1969

In 1969 it was evident that the incidence of gonorrhoea showed a more pronounced increase than at any time after the second world war. The aim of the supplementary count was:

(1) To evaluate the number of repeaters;

(2) To make a rough estimate of the number of male patients who contracted gonorrhoea by homosexual contact.

\section{Re-infections}

Among 6,840 males who became infected with gonorrhoea during 1969, 404 (5.9 per cent.) were repeaters, and of these 56 had gonorrhoea three times or more during that year. Among 5,960 females, 298 ( 5.0 per cent.) were registered more than once, and of these 33 had gonorrhoea three times or more.

Males with gonorrhoea contracted by homosexual contact A rectal (R) specimen was examined from 844 (12 per cent.) of 6,840 male patients with gonorrhoea; in 24 positive cases $(0.4$ per cent. of all male cases), the rectal specimen was the only one examined. Out of 820 patients from whom both $U$ and $R$ specimens were examined, the $U$ specimen was the only one positive in 714 cases ( 87 per cent.), the $R$ specimen the only one positive in 84 cases ( 10 per cent.), and both specimens were positive in 22 cases ( 3 per cent.). Thus, a total of 130 had rectal gonorrhoea, corresponding to 2 per cent. of all male patients with gonorrhoea $(130 / 6,840)$ and to 15 per cent. of the cases in which a rectal specimen was examined $(130 / 844)$.

Isolation of $\mathrm{N}$. gonorrhoeae from unusual sites Requests for examination of non-urogenital specimens for $N$. gonorrhoeae have become more frequent during the last 2 years (1971 and 1972). Generally the specimens are from the pharynx or the tonsils. In 1971 a growth of gonococci was obtained from 102 pharyngeal/tonsillar specimens from 72 patients (28 females and 44 males). Concomitant urogenital infection was demonstrated in 26 of the 28 females. In 32 of the 44 male patients, either a $U$ (29) or an $R$ specimen (3) was infected simultaneously.

During the first three quarters of 1972, a total of 189 pharyngeal/tonsillar specimens were found positive.

\section{Discussion}

The incidence of gonorrhoea in Denmark, excluding Greenland, is now about 300 cases per 100,000 inhabitants. The number of cases reported showed a further increase in the first months of 1972. The morbidity in Copenhagen is about three times the mean value (unpublished data).

In Sweden, an increase in the morbidity of gonorrhoea has been evident for more than 10 years. 
The annual number of reported cases is about 500 per 100,000 (Juhlin and Wallin, 1972). In Western Europe the incidence began to rise after the mid 1960s (Guthe, 1972). In some countries (e.g. France), this tendency cannot be seen from the official figures. This may be due to a tradition of significant 'under-reporting' (Guthe, 1972; Siboulet, 1972). In most countries, four to ten cases are reported among males for each female case. In Denmark the male/ female ratio is $1 \cdot 4: 1$ for reported cases and $1 \cdot 1: 1$ for cases registered at the Neisseria Department, indicating that a comparatively large proportion of the actual cases is revealed.

An analysis of the age distribution curves for registered cases showed a constant picture, with the peaks for female patients at 19 to 20 years of age and for male patients at 23 to 24 years of age (Fig. 3). The statistical analyses were based on 5-year age groups, and were performed only for the exposed age groups between 15 and 40 years old. The only group showing changes that were significantly different from the others was the 15 to 19-year-old females. The morbidity curve for that group showed a small peak around 1960-1961. At the same time, the number of persons in that group was high because of the very high birth rates in Denmark in the years 1944-1947. As a result 43 per cent. of all cases of female gonorrhoea in 1961 were 'teenagers'. Since 1968 the morbidity in the same group has increased dramatically and is at present 1,672 per 100,000 , i.e. the highest value demonstrated for any 5 -year age group in 1971. This can only partly be explained by the fact that the increase in morbidity is higher in the rural districts where the mean age is low (Lind, 1962).

The increasing incidence of gonorrhoea could not be correlated with an increase in the registered number of repeaters. In 1969 the percentage of reinfections was about 5 per cent., whereas it was about 4 per cent. in 1957 (Lind, unpublished data). Neither could the number of males contracting gonorrhoea homosexually be related to that found for syphilis in Denmark (39 per cent. in the period 1965-1969) (Jørgensen, 1970). A rough estimate of homosexually acquired gonorrhoea based on the number of registered cases of male rectal gonorrhoea and on the figures for preferred roles in homosexual contacts given by Owen and Hill (1972), is 5 per cent. However, since only 12 per cent. of the male patients with gonorrhoea were examined by rectal culture, this figure must be a minimum value.

During the past 2 years, several reports have been published concerning pharyngeal gonorrhoea. Reports from Sweden (Hellgren, 1971) and Denmark (Bro-Jørgensen and Jensen, 1971) show that gonococci are isolated with the same frequency from female and male patients, whereas in the U.S.A. (Owen and Hill, 1972) and England (Rodin, Monteiro, and Scrimgeour, 1972) the studies have been concentrated on this site in male homosexuals. In 1971 a total of 72 cases of pharyngeal gonorrhoea were registered at the Neisseria Department (28 females and 44 males). This figure will be considerably higher in 1972.

\section{Summary}

All cases of gonorrhoea in Denmark in which the diagnosis is based on culture of gonococci are registered at the Neisseria Department, Statens Seruminstitut, Copenhagen. From 1957 to 1971 the annual number of registered cases rose from about 4,000 to more than 15,000 . Since 1960 the number of registered cases of gonorrhoea in women has been higher than that reported to the National Health Service (1971: +15 per cent.). The number of reported cases of gonorrhoea in men has constantly exceeded the number of cases in which the diagnosis was confirmed by culture of gonococci (1971: +13 per cent.).

A breakdown by age of patients with gonorrhoea showed that, since 1968, the increase in morbidity was most pronounced for 15 to 19-year-old girls. In 1971 the highest values were found for 15 to 19 year-old girls $(1,672$ cases per 100,000) and for 20 to 24-year-old men (1,619 cases per 100,000). The morbidity in Copenhagen was about three times as high as that found for the rest of the country.

Based on registered cases of male rectal gonorrhoea, the frequency of homosexually acquired gonorrhoea in men was roughly estimated to be at least 5 per cent. of all cases. In 1971 pharyngeal gonorrhoea was demonstrated in 28 females and 44 males.

\section{References}

Bro-Jørgensen, A., and Jensen, T. (1971) Brit. med. F., 4,660

Guthe, T. (1972) Postgrad. med. F., 48 (January suppl. 1), p. 7

HeLLGREN, L. (1971), Läkartidningen, 68, 569

Jørgensen, B. B. (1970) Personal communication

Juhlin, L. and Wallin, J. (1972) Postgrad. med. F., 48 (January suppl. 1), p. 12

LiND, I. (1962) Proc. north. derm. Soc., p. 53

- (1967) Acta path. microbiol. scand., 70, 613

- (1969) Ibid., 76, 279

Owen, R. L., and Hill, J. L. (1972) f. Amer. med. Ass., 220, 1315

ReYN, A. (1969) Bull. Wld Hlth Org., 40, 245

- and Bentzon, M. W. (1972) Brit.F. vener. Dis., 48, 363 
Rodin, P., Monteiro, G. E., and Scrimgeour, G. (1972) Ibid., 48, 182

SibOULET, A. (1972) WHO/VDT/72.377

\section{L'incidence de la gonococcie au Danemark de 1957 à 1971}

\section{SOMMAIRE}

Tous les cas de gonococcie au Danemark pour lesquels le diagnostic repose sur la culture du gonocoque, sont enregistrés au Département des Neisseria, Statens Seruminstitut, Copenhague. De 1957 à 1971, le nombre annuel de cas enregistrés est passé d'à peu près 4.000 à plus de 15.000. Depuis 1960, le nombre des cas enregistrés de gonococcie chez la femme a été plus élevé que celui des cas déclarés au Service National de Santé $(1971:+15$ pour cent). Le nombre des cas déclarés de gonococcie chez l'homme a constamment dépassé le nombre de ceux pour lesquels le diagnostic avait été confirmé par la culture de gonocoques (1971: + 13 pour cent).

En groupant les gonococciques selon l'âge, on voit que depuis 1968 l'augmentation de la morbidité a été plus prononcée chez les femmes de 15 à 19 ans. En 1971, les plus hauts chiffres furent trouvés chez les femmes de 15 à 19 ans (1.672 cas pour 100.000) et chez les hommes âgés de 20 à 24 ans (1.619 cas pour 100.000). La morbidité à Copenhague fut environ trois fois plus élevée que celle trouvée dans le reste du pays.

Sur la base des cas enregistré de gonococcie rectale masculine, la fréquence de gonococcies acquises par homosexulaité chez les hommes, fut, en gros, estimée à au moins 5 pour cent de l'ensemble des cas. En 1971, une gonococcie pharyngée fut trouvée chez 28 femmes et chez 44 hommes. 